\title{
The Lifespan of Humans and Animals Can Be Significantly Extended
}

\author{
*Evžen Korec MSc. Ph.D. \\ Director, Department of Genetics ZOO Tábor, Czech Republic
}

Received: October 02, 2017; Published: October 04,2017

*Corresponding author: Evžen Korec, MSc. Ph.D., Director, Department of Genetics, Z00 Tábor, Dukelských hrdinů 19, Prague 7, 170 00, Czech Republic, Tel: +420 233372 021; E-mail: director@zootabor.eu

\section{Opinion}

The average lifespan of animals varies greatly from a few days to hundreds of years. The Antarctic sponge Cinachyra Antarctica has lived for 1550 years, the Arctica Islandica clam for more than 400 years. The longest-living vertebrate is the Aldabra giant tortoise (Aldabrachelys gigantea), which can live for more than 200 years. The longest-living mammal is the bowhead whale (Balaena mysticetus) (up to 200 years). Another long-live mammal is an elephant, who lives up to 70 years. People in more economically developed countries normally live for 80 years, but there is a group of people over the age of 100 years. We can also find enormous lifespan differences among birds. The golden eagle (Aquila chrysaetos) lives up to 80 years, the large parrots Ara up to 70 years old, while the small songbirds live 5-10 years.

The shortest life has a mayfly (Ephemeroptera) (1-3 days), unless we don't count the time when the mayfly was a nymph. The short-live mammals are rats (2-4 years) and hamsters (2-3 years). In the animal kingdom the rule is that larger animals live longer, but this rule has a number of exceptions. The purebred dogs make one of the exceptions where, on the contrary, dogs of higher weight live shorter life.

It is very likely that the secrecy of longevity is determined in genes. The information about how long will the animal live is written in the genome of all animals. This information is specific and different for each species. It was formed during hundreds of millions of years of evolution and is determined to provide the best conditions for the survival of the species, not the survival of the individual.

Today we are at the beginning of the process of identifying and analysing genes responsible for longevity. The first genes related to longevity have already been discovered in mice and humans. Once our knowledge of genes responsible for longevity is expanded, it is realistic to imagine the possible use of this knowledge to significant extension of the lifespan of humans and animals.

A simple model can be imagined that information about how long will the animal live and when it will die is coded in the genome of each organism. One can imagine finding a regulatory mechanism that slows down reading of this information or even reverse that process that will result in the body rejuvenation. The jellyfish of the species turritopsis proves that this is not just science fiction. In this jellyfish a mechanism has been found that allows the jellyfish at the end of its life to become a juvenile again and return to the stage of the polyp. The jellyfish uses this mechanism for example to prevent death due to lack of food. This is undoubtedly the possibility to change the reading of genetic information caused by stimuli from the external environment. A detailed explanation of this mechanism at the molecular-genetic level may be the first step in the process of understanding how to influence the reading of genetic information causing aging.

Another promising way to prolong life is discovery of anti-aging agents. The first discovered anti-aging agent that has prolonged the life of experimental animals is rapamycin, which was previously used in medicine as a means to suppress immune response after transplantation. Here we are also at the beginning of the journey. At its end there will be agents that will significantly slow down the aging process and allow a prolonged life.

The way to a significant prolongation of life and almost immortality is shown in the process of transforming a differentiated cell into a tumour cell. If the tumour cells in the tissue structure have sufficient nutrient supply, these cells are immortal. The molecular-genetic principle of tumour cell formation is a change in reading genetic information. The differentiated cell stops reading the information corresponding to the differentiated cell but instead reads the information corresponding to dedifferentiation and rapid division. Similar information was read by the embryo cell at the time of fertilization of the egg.

Knowing the process of tumour cell formation at the molecular level will in the future allow not only effective cancer treatment but also understanding the principles of regulation of reading genetic information that could bring a significant life extension. 


\begin{tabular}{ll} 
BIOMEDICAL & Assets of Publishing with us \\
RESEARCHES & Global archiving of articles \\
\hline & - Immediate, unrestricted online access \\
\hline
\end{tabular}

